\title{
Effects of Straight and Serpentine Flow Field Designs on Temperature Distribution in Proton Exchange Membrane (PEM) Fuel Cell
}

\author{
Izzuddin Zaman ${ }^{1}$, Bukhari Manshoor ${ }^{2, *}$, Amir Khalid ${ }^{2}$, Laily Azwati Mohamad Sterand ${ }^{2}$, \\ and Shiau Wei Chan ${ }^{3}$ \\ ${ }^{1}$ Structural Integrity and Monitoring Research Group, Faculty of Mechanical and Manufacturing \\ Engineering, Universiti Tun Hussein Onn Malaysia, 86400 Batu Pahat, Johor, Malaysia \\ ${ }^{2}$ Centre for Energy and Industrial Environment Studies, Faculty of Mechanical and Manufacturing \\ Engineering, Universiti Tun Hussein Onn Malaysia, 86400 Batu Pahat, Johor, Malaysia \\ ${ }^{3}$ Faculty of Technology Management and Business, Universiti Tun Hussein Onn Malaysia, 86400 \\ Batu Pahat, Johor, Malaysia
}

\begin{abstract}
Proton exchange membrane fuel cells or sometimes called as polymer electrolyte membrane (PEM) fuel cells is a device for energy transformation in a changing process from one form of energy to another form of energy. It became as an alternative especially for future use in stationary and vehicular applications. PEM fuel cells provide high efficiency and power density with null emission, low operating temperature, quickly start and long life. One of the aspects that are crucial in optimizing the PEM fuel cells performance is a flow field geometry. In this paper, a simulation case of PEM fuel cells was simulated to determine effects of a straight and serpentine flow field on temperature distribution in PEM fuel cells. ANSYS Fluent software was used to simulate 3dimensional models of single PEM fuel cells in order to determine the effects of changes in the geometry flow field on temperature distributions. Results showed that the serpentine flow field design produces a better temperature distribution along the membrane. The simulation result shows a good agreement with the experiment, thus boost a higher confidence in the results to determine the effectiveness of the flow field design in PEM fuel cells.
\end{abstract}

\section{Introduction}

One of the most significant aspects of developing a fuel cells design is modeling concept that calculation which makes it possibility investigate complex geometries and various circumstances by spending less time and effort from attempt investigation [1]. Basically, the operation concept of fuel cells can be distinguished as a transportation of gas-mixture and transformation of species through a process of change of electrochemical circumstances. In this process, hydrogen from anode flow channel will be transported through the Gas Diffusion Layer (GDL) toward Membrane Electrode Assembly (MEA)

\footnotetext{
*Corresponding author: bukhari@uthm.edu.my
} 
surface. In Catalyst Layer (CL), hydrogen molecules will dissociate to proton and electrons, as the reaction of hydrogen CL can be shown as follow.

$$
H_{2} \rightarrow 2 H^{+}+2 e^{-}
$$

From the above relation, water that fertilizes the MEA will hydrate the protons, hence the process of an electro-osmosis and diffusion will transport water in MEA. At the same time, the mixture of air in cathode channel will transport through the GDL toward the MEA where the reaction occurs between oxygen and proton. This reaction will produce water as in reaction shows below.

$$
\frac{1}{2 \mathrm{O}_{2}}+2 \mathrm{H}^{+}+2 e^{-} \rightarrow \mathrm{H}_{2} \mathrm{O}
$$

The oxygen received an electron from one electrode and hydrogen will supply the electron to another electrode. This flow can generate electrical power for an automobile or other electrical devices. This system saves the environment because the waste product of the PEM fuel cells only contains a water, as showed in the chemical reaction above.

In the fuel cells systems, there are several thing that needs to avoid in order to keep the performance of the fuel cells and also to evade the system from the failure. Basically, the common failure occurs in the fuel cells system includes a chemical degradation of the ionomer membrane or mechanical failure in the PEM. This failure can cause a gradual reduction ionic conductivity, increasing the total cell resistance, reduction of voltage and the power output also may lose or decrease [2, 3]. Therefore, thermal management is important to control the rate of water evaporation or condensation from the system. By control the temperature and humidity, the PEM, gas diffusion layer (GDL) and bipolar plates will all experience expansion and contraction. Resulting from the thermal expansion and contraction, hydrothermal stresses will be introduced into the cell unit during operation.

In addition, the distribution of the current flow and the reactants are not uniform in cell temperature and humidity can cause a non-uniform content of the cell and at the same time have a potential to cause a localized increase in the magnitude of the pressure. According to Hashemi et.al [4], temperature distribution in the fuel cells are highly dependent on the charge and also the activity during the electrochemical reaction. At high current density, the fuel cells were performed badly while the membrane thickness provide a better performance at low current density [5,6]. Membranes have some resistance to the passage of protons from the anode to the cathode. The resistance will decrease when the membrane thickness decreased, hence the deformation due to thermal stress is low. However, the thin membrane has increased the cross gas problems, thus, will lead to a reverse flow and degradation of the temperature and membrane.

\section{Simulation models}

In order to increase the performance of the PEM fuel cells, one of the important aspects that needs to be considered in water management is the design of the flow channel. In this study, a numerical simulation based on 3-dimensional models will be performed. Several assumption had been considering to make sure the simulation can be performed easily. Among the assumption made are;

1) The cells were operating under the steady state condition.

2) The temperatures of cell are uniform and fix. 
Figure 1 illustrates a schematic diagram of the PEM fuel cells, which is the typical design that will use for the simulation. The main part in PEM fuel cells consist three main parts, which are an anode, a cathode and polymer electrolyte membrane. There have three distinct regions at the anode and cathode. The region consists of the gas channel, gas diffuser, and catalyst layer, as shown in the diagram.

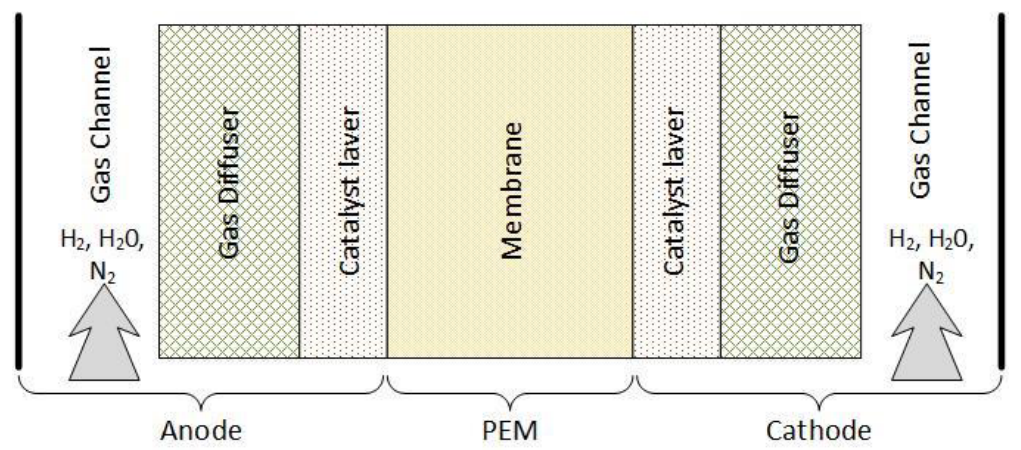

Fig. 1. Schematic diagram of a PEM fuel cell [7].

In the research of improvement of the PEM fuel cell performance, a number of experiment and numerical efforts have been devoted for it especially for water management inside the PEM fuel cells for steady state and transient condition as reported in [8-10]. However, their flow-field effect in the performance is absent from literature. To optimize the flow-field design, hopefully, the research of flow patterns inside the PEM fuel cells will give an idea to fix the lacking of absent from previous research.

\section{Simulation work}

As shown in Figure 1, the PEM fuel cells have a three main parts. There are an anode, PEM and cathode. For both anode and cathode, it contains a gas channel, gas diffusion and catalyst layer and both are divided by PEM at the middle of the fuel cell. Humidified air will be fed into the cathode channel, whereas hydrogen is supplied to the anode channel. For this study, the authors were concentrating on the flow channel that used to flow an oxygen and hydrogen through the PEM fuel cell. Figure 2(a) shows the view of gas flow channel in this research. There are divided into two part flows which are an anode side flow channel and a cathode side flow channel. Both channels have same parameter which is $0.3 \mathrm{~mm}$ for the dimension channel.
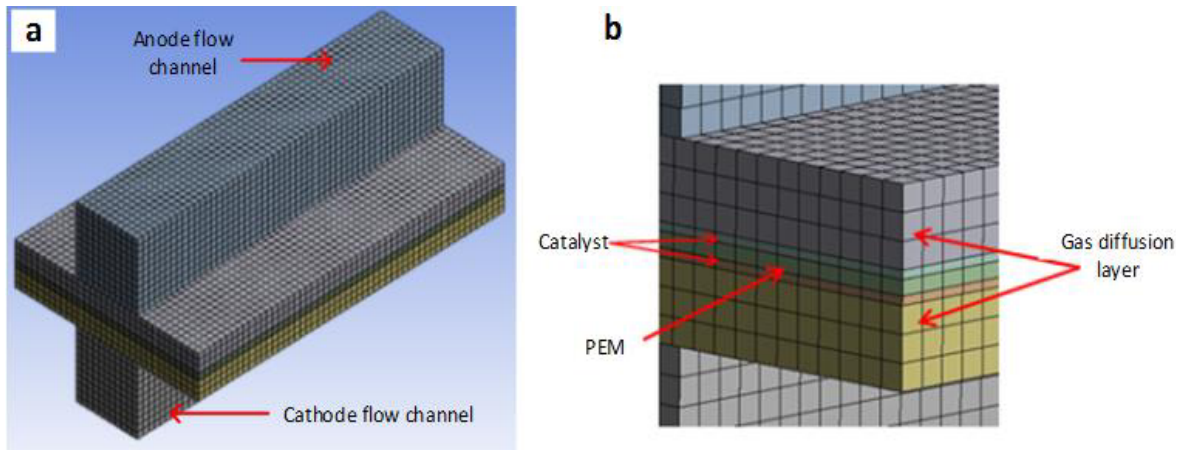

Fig. 2. (a) 3-D computational of PEMFC flow channel, (b) Computational domain of PEMFC. 
Figure 2 shows the 3-dimensional meshed model of the PEM fuel cell flow channel. From the figure, it is more clearly showed the components in the system which are anode and cathode flow channel and both of the flow channel contain of gas diffusion layer and catalyst layer that separated by the PEM. The membrane (PEM) at the middle part is the main part of this system which is hydrogen separated with an electron and start to transfer to the catalyst layer at the cathode part.

The boundary conditions used are summarized in Table 1 . The modeling is done with the available condition in research by Al-Baghdadi [3] and Hashemi et. al [4]. The simulation parameter that used in this study also referred to research that had been done by Hossain et. al [11], which was used an Ansys DM version 15.1 as their modeler. Ansys mashing set up as default, size function and smoothing as fixed and medium with slow transition. Fluent 3-D single precision with solver type as pressure based.

Table 1. Geometry and operational parameter

\begin{tabular}{|l|l|c|}
\hline Parameter & Symbol & Value \\
\hline Cell length & $\mathrm{L}_{\text {cell }}$ & $5 \mathrm{~mm}$ \\
\hline Cell width & $\mathrm{W}_{\text {cell }}$ & $5 \mathrm{~mm}$ \\
\hline Gas Channel width & $\mathrm{W}$ & $0.3 \mathrm{~mm}$ \\
\hline Gas Channel height & $\mathrm{H}$ & $0.3 \mathrm{~mm}$ \\
\hline Gas diffusion layer thickness (GDL) & ${ }^{\delta} \mathrm{GDL}$ & $0.26 \mathrm{~mm}$ \\
\hline Wet membrane thickness (PTFE) & ${ }^{\delta}$ mem & $0.05 \mathrm{~mm}$ \\
\hline Catalyst layer thickness (CL) & ${ }_{\mathrm{CL}}$ & $0.0287 \mathrm{~mm}$ \\
\hline Anode and cathode pressure & $\mathrm{P}_{\mathrm{a}}$ and $\mathrm{P}_{\mathrm{c}}$ & $1 \times 10^{5} \mathrm{~Pa}$ \\
\hline Initial temperature both inlet & $\mathrm{K}$ & 353.15 \\
\hline Porosity of GDL & - & 0.8 \\
Porosity of CL & - & 0.6 \\
Porosity of Membrane & - & 0.4 \\
\hline Operating pressure & $\mathrm{Pa}$ & 101325 \\
\hline Mass flow rate: & & $6.0 \mathrm{e}-7$ \\
Anode & $\mathrm{kg} / \mathrm{s}$ & $5.0 \mathrm{e}-6$ \\
Cathode & & \\
\hline
\end{tabular}

Model flow is turbulent because the Reynolds number more than 4000 with fluid Hydrogen and Oxygen while at wall solid set up as Aluminum with constant temperature. However, we assume it laminar cause of the channel is very small. By using the turbulent model, the accuracy of performance will decrease. Scheme for solution method is SIMPLE method with spatial discretization Green-gauss node based; standard pressure and solution initialization is hybrid with 150 iterations.

\section{Results and discussion}

The simulation work had been done for two cases of flow which are serpentine flow and straight flow. The results that were come out from this research are the distribution of temperature for both cases. Figures 3(a) and 3(b) show the distribution of the local contour temperature on membrane plane surface in straight gas flow channel and serpentine gas flow channel. For the straight gas flow channel, it showed that the temperature distributes from $353.155 \mathrm{~K}$ near at inlet anode and decrease to $353.148 \mathrm{~K}$ near the outlet anode. However for the range of serpentine gas flow channel, the temperature distribute from $353.147 \mathrm{~K}$ near at inlet anode while decrease to $353.132 \mathrm{~K}$ near the outlet anode. 


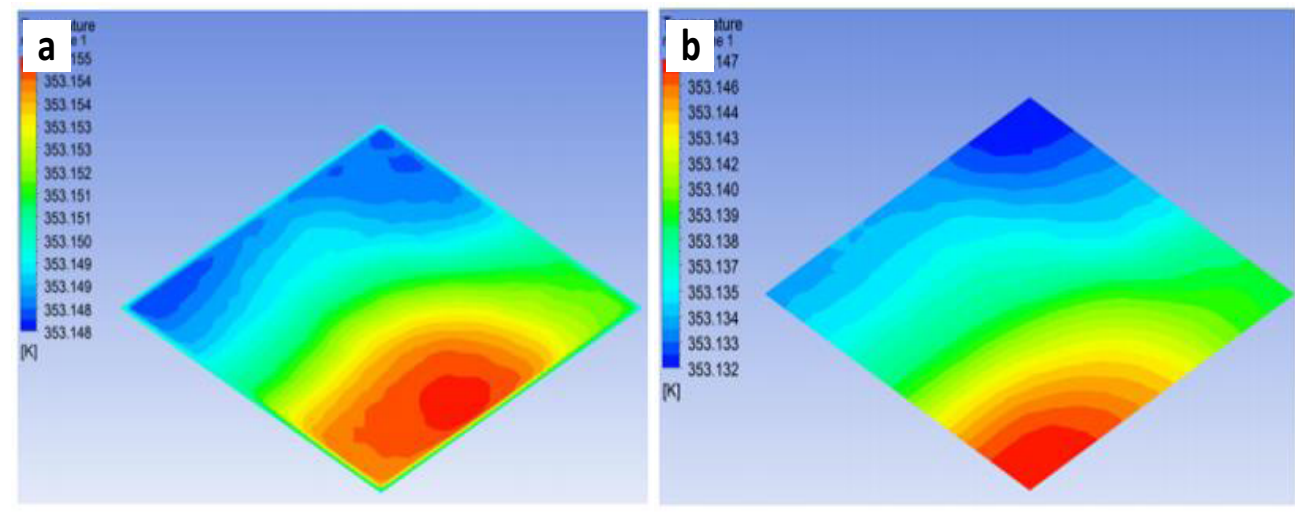

Fig. 3. Distribution of the temperature at membrane (a) straight gas channel (b) serpentine gas channel.

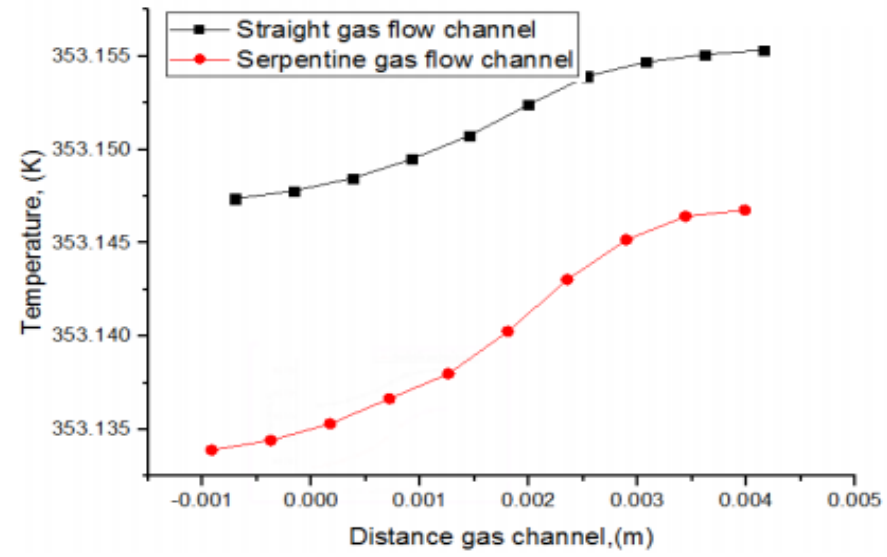

Fig. 4. The plot of temperature

distribution against distance gas channel (m).

Although the different temperature change at the anode and cathode are small for both case, it was showed that the straight and serpentine gas flow channel gave a significant effect on the temperature distribution on the membrane. The small change of the temperature basically due to the thickness of membrane which is $5 \mathrm{~mm}$. In a real case, the membrane can be thinner and an assumption had been done for this simulation work to choose a thickness of the membrane up to $5 \mathrm{~mm}$ so that it easy to model and simulate the problem regarding the PEM fuel cell.

From the images shown in Figure 3, the decreasing of temperature occurred from the middle of the membrane surface. This is because the hydrogen will flow through the catalyst layer from the anode side to the cathode side which is the area where the oxygen is supplied. The oxygen will combine with the hydrogen during the process and a water will be produced as a waste product. Figure 4 shows the temperature distribution for both channels of straight and serpentine flow. Since there is no chemical reaction occurred at the inlet for both channels, the temperature was higher at the location. The thickness of membrane also give effect of temperature distribution. Membrane thickness decreased, resistance decrease and temperature will drop. 


\section{Conclusion}

As performed in this study, the simulation of two flow-field design configuration and effect between two designs on PEM fuel cell performance were presented. The temperature distribution along the membrane in PEM fuel cells for serpentine gas flow channel and straight gas flow channel were analyzed. In conclusion, the changing flow-field design or pattern of PEM fuel cell can give an effect to the temperature distribution and other characteristic that need to be consider in order to improve the performance of PEM fuel cells. The serpentine flow-field gives more uniform temperature distribution compare with straight flow-field. This is due to the shape of gas channel for serpentine is direct from inlet to outlet, compare to straight gas flow channel, the gas fed from inlet and gas distribute by channel and it maybe not constant when it distribute.

Partial support was provided by MOHE (Ministry of Higher Education, MALAYSIA) and Universiti Tun Hussein Onn Malaysia (UTHM) under the Fundamental Research Grants Scheme (FRGS), vote 1466 and Incentive Grant Scheme for Publication (IGSP), vote U247.

\section{References}

1. N. Djilali, Energy, 32, 269 (2007)

2. V. Mehta, J.S. Cooper, J. Power Sources, 114, 32 (2003)

3. M.A.S. Al-Baghdadi, International Journal of Energy and Environment, 5, 1 (2014)

4. F. Hashemi, S. Rowshanzamir, M. Rezakazemi, Math. Comput. Model., 55, 1540 (2012)

5. B.M. Koraishy, J.P. Meyers, K.L. Wood, J. Electrochem. Soc., 158, 1459 (2011)

6. A.K. Sahu, S. Pitchumani, P. Sridhar, A.K. Shukla, Fuel Cells, 9, 139 (2009)

7. S. Um, C.Y. Wang, K.S. Chen, J. Electrochem. Soc., 147, 4485 (2000)

8. P.R. Pathapati, X. Xue, J. Tang, Renew. Energ., 30, 1 (2005)

9. D.H. Jeon, S. Greenway, S. Shimpalee, J.W. Van Zee, Int. J. Hydrogen Energ., 33, $1052(2008)$

10. S.Y. Cha, W.M. Lee, J. Electrochem. Soc., 146, (1999)

11. M. Hossain, S.Z. Islam, A. Colley Davies, E. Adom, Renew. Energ., 50, 763 (2013) 